\title{
EFFICACY AND SAFETY OF MULTITARGETED KINASE INHIBITORS IN PROGRESSIVE, RADIOIODINE-REFRACTORY DIFFERENTIATED THYROID CANCERS: A META-ANALYSIS
}

\author{
Mutahir A. Tunio ${ }^{1}$, Mushabbab AlAsiri ${ }^{1}$, Yasser Bayoumi ${ }^{2}$ \\ ${ }^{1}$ Department of Radiation Oncology, Comprehensive Cancer Center, King Fahad Medical City, Riyadh, KSA, \\ ${ }^{2}$ Department of Radiation Oncology, $\mathrm{NCl}$, Cairo University, Cairo, Egypt
}

Received: 19 March 2015 / Accepted: 20 April 2015

\begin{abstract}
Purpose: A meta-analysis was conducted to evaluate the impact of oral multitargeted kinase inhibitors (MTKIs) in radioactive-iodine refractory locally advanced, recurrent/metastatic differentiated thyroid cancer (DTC) on disease control rate (DCR), progression-free survival (PFS) and overall survival (OS) rates.

Materials and Methods: The PubMed/MEDLINE, CANCERLIT, EMBASE, Cochrane Library database and other search engines were searched to identify randomised controlled trials (RCTs) comparing MTKIs with placebo in locally advanced, recurrent/metastatic DTC. Pooled data were expressed as odds ratio (OR), with $95 \%$ confidence intervals (CIs, Mantel-Haenszel fixed-effect model).

Results: Three RCTs with a total patient population of 954 patients were identified. The use of MTKIs was associated with improved PFS (OR: 0.262, 95\% CI: 0.19-0.35; heterogeneity (I2) $=22.4 \% ; P<0.0001$ ), improved DCR (complete and partial responses + stable disease, $P<0.0001)$ and improved OS 0.66, 95\% CI: $0.46-0.96$ (I2 $=43 \%, P=0.034)$. Lenvatinib (compliance $=87 \%$ ) was associated with more grade $\geq 3$ hypertension. However, its other adverse effects were much lower than sorafenib (compliance $=56 \%$ ) and vandetanib.
\end{abstract}

Conclusion: In radioactive iodine-refractory recurrent, metastatic DTC patients, lenvatinib and sorafenib were associated with improved PFS, DRC and OS rates, while the compliance was better with lenvatinib.

Key words: Meta-analysis, multitargeted kinase inhibitors, progressive differentiated thyroid cancer, radioactive iodinerefractory

\section{Introduction}

Differentiated thyroid cancers (DTC), which include papillary, follicular and poorly differentiated subtypes, constitute $90 \%$ of all thyroid malignancies. ${ }^{[1]}$ DTC has generally an excellent outcome after the traditional treatment which includes surgery, thyroid-stimulating hormone suppression therapy and radioactive iodine (RAI) therapy and, in some cases, radiation therapy. ${ }^{[1]}$ Despite this, $10 \%-25 \%$ of DTC patients experience locoregional recurrence and distant metastasis which need additional treatment measures in the form of surgery or RAI for

Correspondence: Mutahir A. Tunio, Department of Radiation Oncology, Comprehensive Cancer Center, King Fahad Medical City, Riyadh - 59046, Saudi Arabia.

Email: mkhairuddin@kfmc.med.sa cure or significant palliation. ${ }^{[2]}$ Patients with iodine-avid recurrent or metastatic disease from DTC may continue to receive multiple sessions of RAI. Subsequently, about two-thirds of such patients become refractory to RAI uptake. ${ }^{[3]}$ Systemic chemotherapy has been found relatively ineffective with poor response rates $(10 \%-$ $37 \%$ ) and has shown to be associated with significant toxicities. ${ }^{[4]}$

During the past decade, aberrant signaling pathways have been investigated in the development, progression and metastasis of DTC such as BRAF and RAS point mutations and rearrangement of the RET protooncogene in papillary cancers; RAS point mutations and rearrangement of the peroxisome proliferator-activated receptor gamma (PPARG) and PAX8 genes in follicular 
cancers and RAS point mutations, endothelial growth factor receptor, vascular endothelial growth factor receptor (VEGFR) overexpression and PIK3CA in poorly differentiated cancers. ${ }^{[5]}$ Identification of these potential targets has led to the development of novel multitargeted kinase inhibitors (MTKIs) for RAI-refractory recurrent, metastatic DTC. ${ }^{[6,7]}$ However, efficacy, safety profile and impact on treatment outcome by MTKIs have not been well studied in DTC patients.

We conducted a meta-analysis to assess the impact of MTKIs in RAI-refractory, locally advanced, recurrent, metastatic DTC on progression-free survival (PFS), disease control rate (DCR), toxicity profile and overall survival (OS).

\section{Materials and Methods}

\section{Studies and study population}

Eligible studies had to be either complete reports of prospective, randomised controlled trials (RCTs) or well-controlled retrospective studies. The abstracts from which full details were available were also included. The PubMed/MEDLINE, CANCERLIT, EMBASE, Cochrane Library database, Web of Science, Academic Search Premier and CINAHL were searched (period 2000-2015) using the terms "(thyroid cancer, DTC, carcinoma), (papillary, follicular, poorly DTC, carcinoma), (tyrosine kinase inhibitors, MTKIs, Sorafenib, Sunitinib, Axitinib, Motesanib, Vandetanib, Pazopanib, Lenvatinib), the efficacy and safety". These terms were then combined to search for eligible studies. The relevant articles were selected by two investigators. Only studies that met the following criteria were included [Figure 1] shows flow diagram of the meta-analysis.

Inclusion criteria were (a) histologically confirmed DTC (papillary, follicular and poorly differentiated cancers), (b) RAI-refractory recurrent or metastatic DTC and (c) treated with oral MTKIs as monotherapy. Patients with DTC who received antiangiogenic drugs other than MTKIs or histone deacetylase inhibitors, PPARG agonists, retinoid receptor agonists and proteasome inhibitors were excluded from the study. Table 1 shows the prospective randomised, phase II/III trials in refractory DTC with MTKIs included in this review. Table 2 shows the application of inclusion and exclusion criteria.

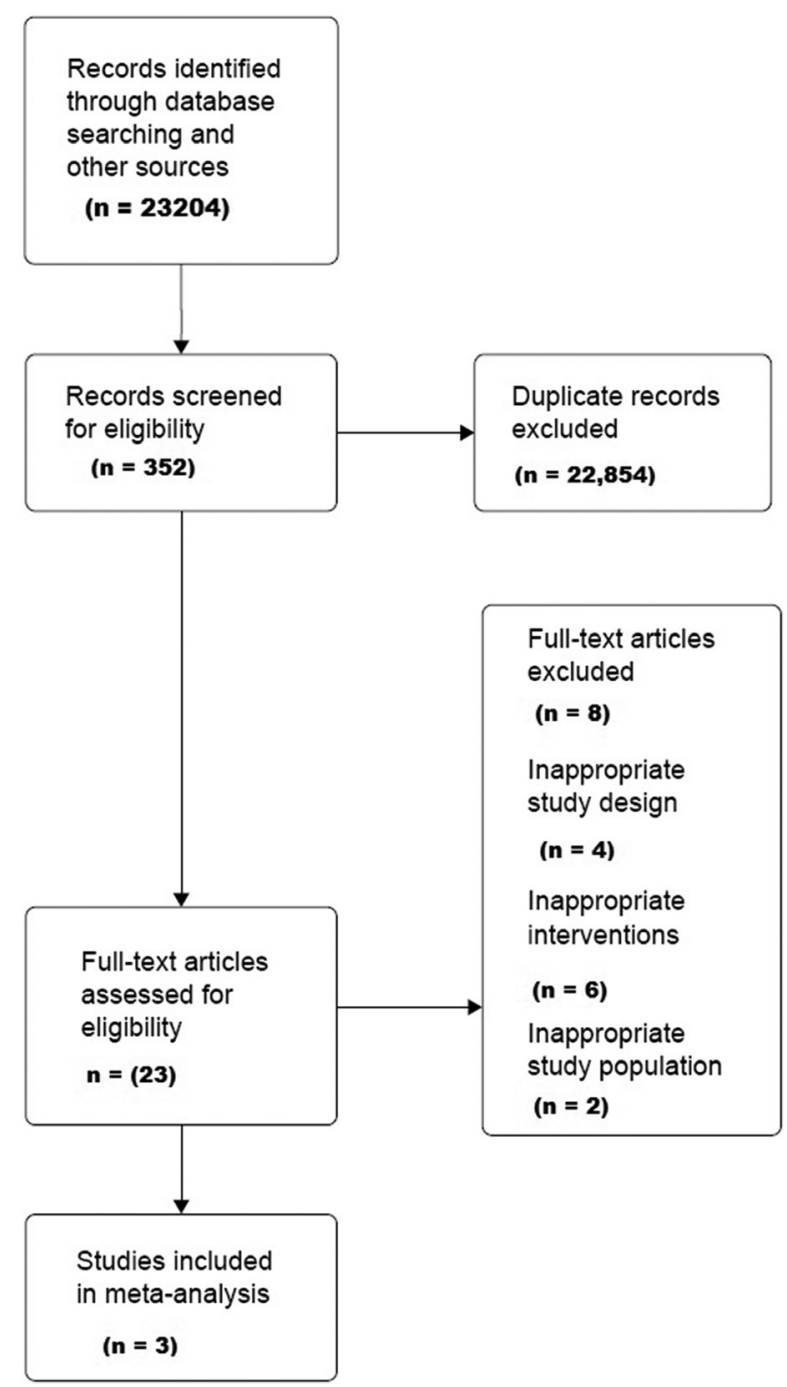

Figure 1: Flow diagram of meta-analysis

\section{Outcome measures and review analysis}

The outcome measures were PFS, DCR, toxicity profile and OS. All analyses were carried out on an intention to treat analysis basis. For the categorical variables, weighted odds ratios (ORs) and their 95\% confidence intervals (95\% CI) were calculated. The results were tested for heterogeneity (I2) using Cochran's Q-test at the significance level of $P$ $<0.05$. If there was evidence of heterogeneity, a random effect model was used for meta-analysis; otherwise, fixed effect model was used. The OR and 95\% CI were calculated for each RCT and presented in forest plot. The DCR was defined as complete response + partial response 


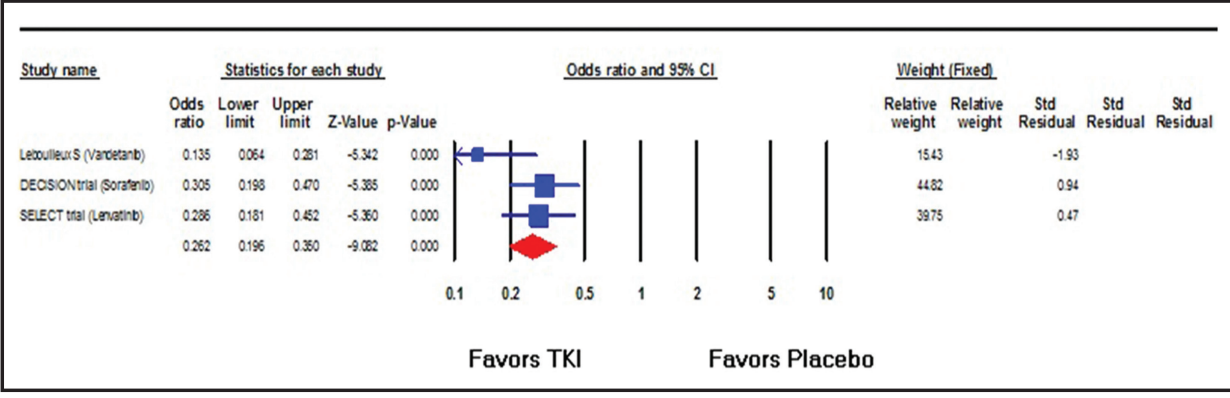

Figure 2: Forest plot for progression-free survival

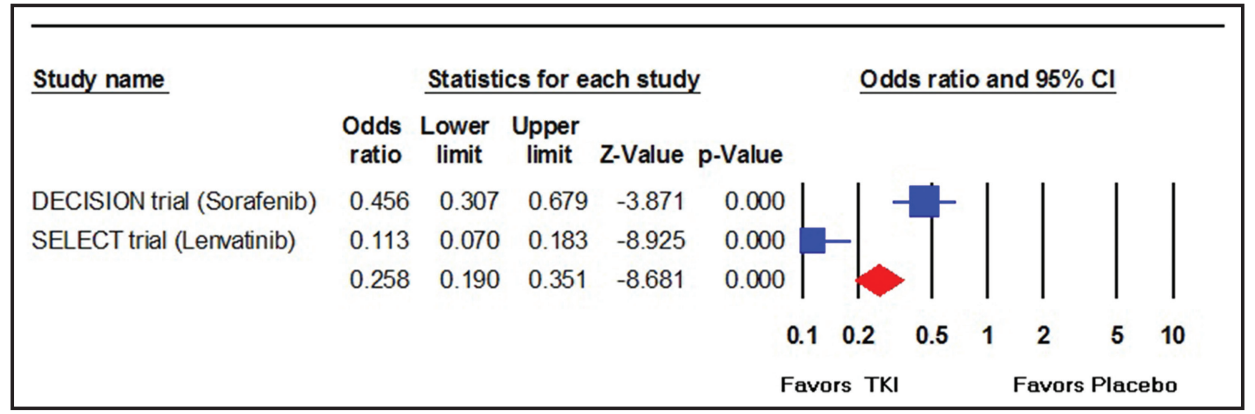

Figure 3: Forest plot for disease control rate

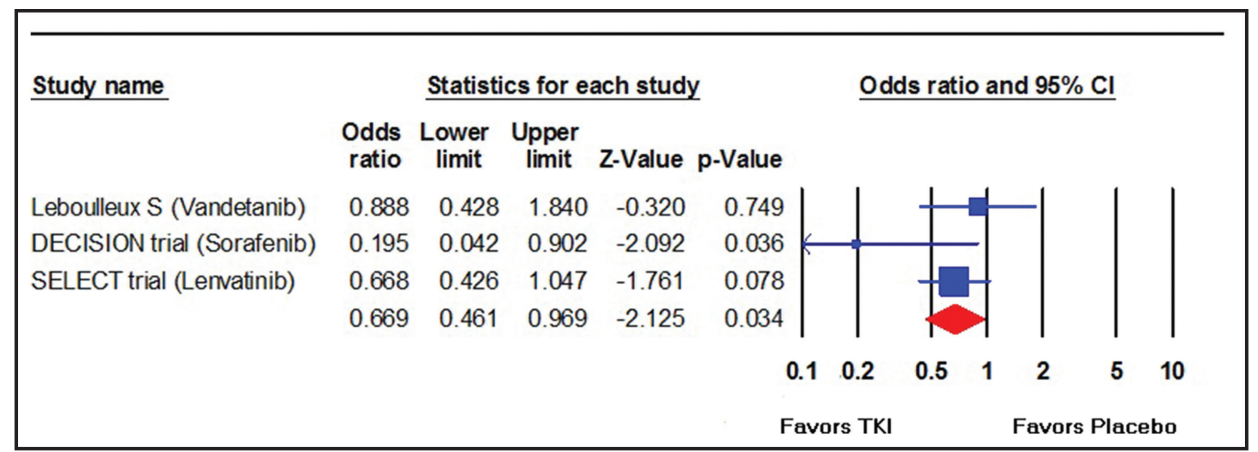

Figure 4: Forest plot for overall survival

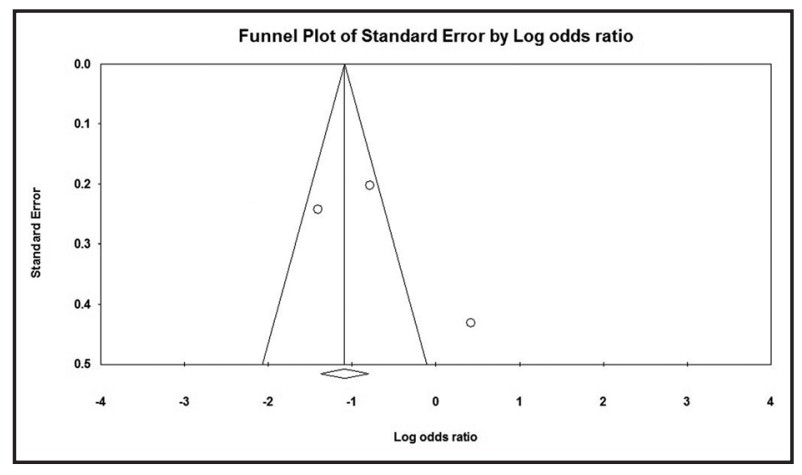

Figure 5: Funnel plot of publication bias
+ stable disease based on Response Evaluation Criteria in Solid Tumours criteria and follow-up period mentioned in each RCT. Publication bias was evaluated using the funnel graph, the Begg-Mazumdar adjusted rank correlation test ${ }^{[8]}$ and the Egger test. ${ }^{[9]}$ All analyses were performed using comprehensive meta-analysis software version 3.3.070.

\section{Results}

The electronic search revealed 23,204 relevant citations, of which 352 were selected. Finally, three RCTs were identified that fulfilled the criteria. 


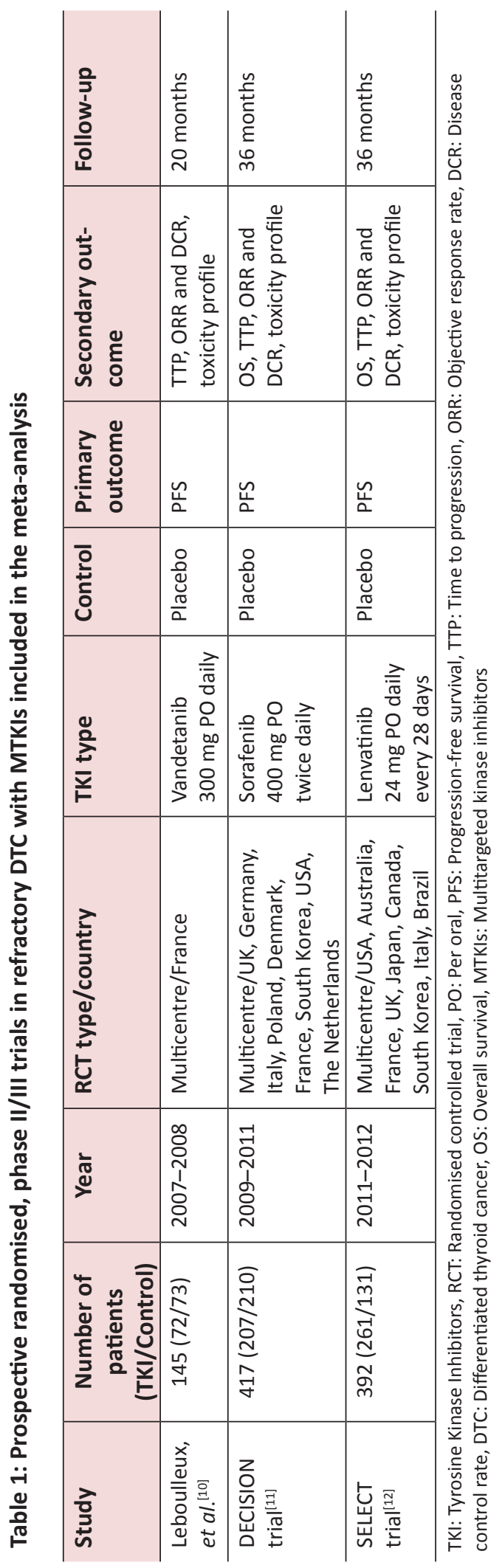

PFS

All three RCTs with a population of 954 patients analysed the PFS rate as one of the outcomes. PFS rates were significantly higher in patients treated with MTKIs, especially lenvatinib and vandetanib $(P<0.0001)$. The pooled OR was 0.262 (95\% CI: $0.19-0.35$; I2 $=22.4 \%)$ [Figure 2].

\section{DCR}

Two RCTs with 809 patients examined the DCR as one of the outcomes. MTKIs, especially lenvatinib, were associated with significantly higher DCR $(P<0.0001)$ [Figure 3].

\section{OS}

All three RCTs, with 954 patients, addressed the OS as one of the outcomes. Two RCTs of sorafenib and lenvatinib showed a significant improvement in the OS, while one RCT of vandetanib showed no survival benefit. The pooled OR was $0.66,95 \%$ CI: $0.46-0.96$ (I2 $=43 \%, P=0.034$ ) [Figure 4].

\section{Toxicity profile}

All three TCTs with 954 patients reported the toxicities, dose reductions and compliance as one of the outcomes. Lenvatinib (compliance $=87 \%$ ) was associated with more Grade 3 hypertension; however, other adverse effects were much lower than sorafenib (compliance $=56 \%$ ) and vandetanib (compliance not reported) Table 3.

\section{Publication bias}

The resultant funnel plot was significantly narrower with statistical significance by Egger test of $P=0.05$ Figure 5 .

\section{Discussion}

In the present meta-analysis, the pooled analysis showed that MTKIs (lenvatinib, sorafenib and vandetanib) significantly improve the PFS and DCR rates, in RAI-refractory DTC patients. Further, lenvatinib and sorafenib showed a trend of increased OS rates. Past experience obtained from using MTKIs has shown that the adverse effects associated with VEGFR inhibition include hypertension, proteinuria, delayed wound healing, bleeding, bowel perforation and thrombosis. ${ }^{[13-15]}$ In the 
Table 2: Inclusion and exclusion criteria of included studies in meta-analysis

\begin{tabular}{|c|c|c|c|c|c|}
\hline Study & Mean age & Inclusion criteria & Exclusion criteria & Previous therapy & Definition of DCR \\
\hline $\begin{array}{l}\text { Leboulleux, } \\
\text { et al. } .^{[10]}\end{array}$ & - & $\begin{array}{l}\text { Aged } \geq 18 \text { years, with } \\
\text { locally advanced/ } \\
\text { metastatic refractory } \\
\text { DTC (papillary, follicular } \\
\text { or poorly differentiated) }\end{array}$ & $\begin{array}{l}\text { Prior targeted ther- } \\
\text { apy, thalidomide or } \\
\text { chemotherapy }\end{array}$ & RAI ablation & $\begin{array}{l}\text { A CR or PR or } \\
\text { durable SD } \\
\text { for } \geq 23 \text { weeks }\end{array}$ \\
\hline DECISION trial ${ }^{[11]}$ & 63 years & $\begin{array}{l}\text { Aged } \geq 18 \text { years, with } \\
\text { locally advanced/ } \\
\text { metastatic refractory } \\
\text { DTC (papillary, follicular } \\
\text { or poorly differentiated) }\end{array}$ & $\begin{array}{l}\text { Prior targeted ther- } \\
\text { apy, thalidomide or } \\
\text { chemotherapy }\end{array}$ & RAI ablation & $\begin{array}{l}\text { A CR or PR or } \\
\text { durable SD } \\
\text { for } \geq 23 \text { weeks }\end{array}$ \\
\hline SELECT trial| ${ }^{[12]}$ & 64 years & $\begin{array}{l}\text { Aged } \geq 18 \text { years with } \\
\text { locally advanced, meta- } \\
\text { static refractory DTC, at } \\
\text { least one measurable } \\
\text { lesion without iodine } \\
\text { uptake on any io- } \\
\text { dine-131 scan }\end{array}$ & $\begin{array}{l}\text { Prior target- } \\
\text { ed therapy or } \\
\text { chemotherapy }\end{array}$ & $\begin{array}{l}\text { RAI ablation within } \\
12 \text { months }\end{array}$ & $\begin{array}{l}\text { A CR or PR or } \\
\text { durable SD } \\
\text { for } \geq 23 \text { weeks }\end{array}$ \\
\hline
\end{tabular}

DTC: Differentiated thyroid cancer, DCR: Disease control rate, CR: Complete response, PR: Partial response, SD: Stable disease, RAI: Radioactive iodine

Table 3: Incidence of toxicity profile $\geq$ Grade 3 in included studies in meta-analysis

\begin{tabular}{l|c|c|c}
\hline Adverse effects & Vandetanib (\%) & 20 & Lenvatinib (\%) \\
\hline Hypertension & - & 11 & 41.8 \\
\hline Diarrhoea & 10 & 11 & 8.0 \\
\hline Fatigue & 12 & 42 & 9.2 \\
\hline Hand-foot syndrome & - & - & 3.4 \\
\hline Proteinuria & - & - & 10 \\
\hline Pulmonary embolism & - & 10 & 2.7 \\
\hline Dyspnoea & - & - & - \\
\hline Decreased appetite & - & 2 & 5.4 \\
\hline Sensory neuropathy & - & 10 & - \\
\hline Skin/desquamation & - & 3 & - \\
\hline Abdominal pain & - & - & - \\
\hline QTc prolongation & 14 & - & 1.5 \\
\hline Pneumonia & 1.5 & - & - \\
\hline Thromboembolic events & - & & \\
\hline
\end{tabular}

present meta-analysis, the incidence of severe hypertension was much higher with Lenvatinib, which warrants its use with extreme caution in hypertensive patients. On the other hand, sorafenib resulted in more Grade $3 \geq$ handfoot syndrome and vandetanib resulted in significant QTc prolongation. Possible explanation for relatively higher adverse effects in DTC patients as compared to patients of renal and hepatocellular cancers treated by similar MTKIs could be the prior multiple RAI sessions or high RAI cumulative dose, which suggests possible radiosensitising effects of MTKIs; ${ }^{[16]}$ however, future Phase I and II trials can give answers by the use of MTKIs in RAI naïve DTC patients. Patient-related compliance was significantly higher with lenvatinib. In contrast to present meta- 
analysis, previous meta-analysis which was conducted by Hesselink et al. was criticised mainly for two reasons (a) primary objective was limited only to response rates and (b) medullary carcinoma of thyroid was not excluded to see absolute benefit of MTKIs in DTC; however, this study concluded that MTKIs in thyroid cancer show a modest response rates; among MTKIs, response rates were promising with Lenvatinib and Vandetanib. ${ }^{[1]}$

The strengths of our meta-analysis were (1) completeness of the search strategy, including searching multiple databases, trial registries and conference proceedings for RCTs comparing MTKIs to the placebo group in RAI refractory locally advanced/metastatic DTC patients; (2) DCR rates and (3) evaluation of the PFS and OS benefit and toxicity profile of MTKIs. The limitations of our meta-analysis were (1) inherent methodological issues in the included trials (risk of bias), (2) attrition bias and (3) reporting bias in included RCTs.

\section{Conclusion}

In view of this meta-analysis and magnitude of the problem of RAI-refractory recurrent, metastatic DTC and efficacy and safety of MTKIs, lenvatinib and sorafenib were associated with improved PFS, DRC and OS rates, while the compliance was better with lenvatinib. However, oncologists and endocrinologists should be aware of proper case selection, adverse effects and precautions, nursing care and frequent follow-ups to improve quality of life and reduce morbidity and mortality in these patients.

\section{Conflict of Interest}

The authors declare that they have no conflict of interest.

\section{References}

1. Schlumberger M, Sherman SI. Approach to the patient with advanced differentiated thyroid cancer. Eur J Endocrinol 2012;166:5-11.

2. Durante C, Haddy N, Baudin E, et al. Long-term outcome of 444 patients with distant metastases from papillary and follicular thyroid carcinoma: Benefits and limits of radioiodine therapy. J Clin Endocrinol Metab 2006;91:2892-9.

3. Shoup M, Stojadinovic A, Nissan A, et al. Prognostic indicators of outcomes in patients with distant metastases from differentiated thyroid carcinoma. J Am Coll Surg
2003;197:191-7.

4. Shimaoka K, Schoenfeld DA, DeWys WD, et al. A randomized trial of doxorubicin versus doxorubicin plus cisplatin in patients with advanced thyroid carcinoma. Cancer 1985;56:2155-60.

5. Kundra P, Burman KD. Thyroid cancer molecular signaling pathways and use of targeted therapy. Endocrinol Metab Clin North Am 2007;36:839-53.

6. Gallo M, Michelon F, Castiglione A, et al. Sorafenib treatment of radioiodine-refractory advanced thyroid cancer in daily clinical practice: A cohort study from a single centre. Endocrine 2015;49:726-34.

7. Cabanillas ME, Schlumberger M, Jarzab B, et al. A phase 2 trial of lenvatinib (E7080) in advanced, progressive, radioiodine-refractory, differentiated thyroid cancer: A clinical outcomes and biomarker assessment. Cancer 2015;121:2749-56.

8. Begg CB, Mazumdar M. Operating characteristics of rank correlation test for publication bias. Biometrics 1994;50:1088-101.

9. Egger M, Smith GD, Schneider M, et al. Bias in metaanalysis detected by a simple graphical test. BMJ 1997;315:629-34.

10. Leboulleux S, Bastholt L, Krause T, et al. Vandetanib in locally advanced or metastatic differentiated thyroid cancer: A randomised, double-blind, phase 2 trial. Lancet Oncol 2012;13:897-905.

11. Brose MS, Nutting CM, Jarzab B, et al. Sorafenib in radioactive iodine-refractory, locally advanced or metastatic differentiated thyroid cancer: A randomised, double-blind, phase 3 trial. Lancet 2014;384:319-28.

12. Schlumberger M, Tahara M, Wirth LJ, et al. Lenvatinib versus placebo in radioiodine- refractory thyroid cancer. N Engl J Med 2015;372:621-30.

13. Bible KC, Suman VJ, Molina JR, et al. Efficacy of pazopanib in progressive, radioiodine-refractory, metastatic differentiated thyroid cancers: Results of a phase 2 consortium study. Lancet Oncol 2010;11:962-72.

14. Cohen EE, Rosen LS, Vokes EE, et al. Axitinib is an active treatment for all histologic subtypes of advanced thyroid cancer: Results from a phase II study. J Clin Oncol 2008;26:4708-13.

15. Sherman SI, Wirth LJ, Droz JP, et al. Motesanib diphosphate in progressive differentiated thyroid cancer. N Engl J Med 2008;359:31-42.

16. Lawrence TS, Nyati MK. Small-molecule tyrosine kinase inhibitors as radiosensitizers. Semin Radiat Oncol 2002;12:33-6.

17. Hesselink EN, Steenvoorden D, Kapiteijn E, et al. Therapy of endocrine disease: Response and toxicity of smallmolecule tyrosine kinase inhibitors in patients with thyroid carcinoma: A systematic review and meta-analysis. Eur J Endocrinol 2015;172:R215-25. 